\title{
Six feet on the ground
}

\section{Munich}

THE University of Bochum has broken new ground with its entry in the competitions for the funds the federal government has set aside for building a new large telescope. But Bochum's daring has attracted critics as well as admirers.

Bochum is hoping to be the beneficiary of an anticipated DM 200 million (\$102 million) the West German government is thinking of spending on a new German Large Telescope (GLT). Theodor Schmidt-Kaler and his colleagues at the university last month revealed a revolutionary "hexapod" design for a large optical telescope. Like all modern telescope designers, Schmidt-Kaler wants to keep both weight and costs down without losing optical quality, but plans to achieve this by building an instrument steered by six legs, all moving independently.

But Klaus Fricke of Göttingen University, leader of a rival group with a conventional design, says "half the world is laughing" at Schmidt-Kaler's proposal, and hopes his group will win the project.

The design for the Bochum hexapod telescope (HPT) was inspired by airline flight simulators, whose position is controlled by piston-like legs. The HPT would have the advantage, according to Schmidt-Kaler, of allowing equally accurate pointing of the telescope across the whole sky. Conventional altitudeazimuth mountings usually have a blindspot overhead.

The second advantage of the HPT is its relatively low weight. Schmidt-Kaler and his colleagues, Gerhard Schur of Bochum and Karl-Heinz Stenvers of Krupp AG, have had been experimenting with lightweight carbon fibres, and claim that if the HPT mounting is made of these materials the total weight of a 1.2-metre-diameter telescope (the size of a planned prototype) need be only 2 tonnes, as against about 30 tonnes for a conventional design. For the 12 -metre telescope that is ultimately planned, this would yield a weight of 120 tonnes, lighter than much smaller conventional telescopes.

The rival project from Fricke's "GLT working group" will be unveiled in the next few weeks. Zeiss AG is collaborating in the project. The proposal is based on a conventional Cassegrain optical system, but uses a new type of segmented mirror. Unlike the US Keck telescope, whose main mirror consists of 36 similar hexagonal elements, the GLT would have a central segment 8 metres in diameter surrounded by smaller mirrors.

Fricke is "extraordinarily sceptical" of the hexapod design. Schmidt-Kaler, he said, is "isolated from the German astronomy community", in part because he "betrayed our interests" by announcing

the HPT so early and by not informing the GLT working group of his plans. Fricke said there had been a tacit agreement not to talk about GLT for two years after the West German Research Ministry agreed in November 1987 to pay a large share of the costs for the Very Large Telescope of the European Southern Observatory (ESO).

Schmidt-Kaler rejects

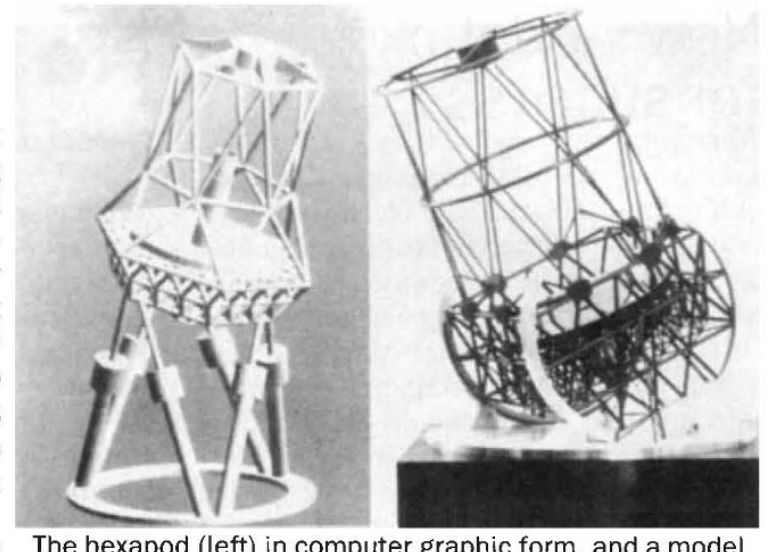
Fricke's assertions. He said that he kept the GLT group informed at all times of his intentions and that he is "convinced" that the HPT project will lead to a large telescope. As far as the timing of the announcement, SchmidtKaler would only say that Krupp had been responsible for that. The telescope race also matches Krupp against Zeiss, two firms known for producing excellent telescope technology.

\section{SCIENCE AND CITIZENS}

\section{An unobtrusive neighbour}

\section{San Francisco}

THE vast medical research, teaching and hospital complex of the University of California at San Francisco (UCSF) has received a clean bill of health from a 20 month environmental study. The study, which cost $\$ 1.6$ million, is likely to help smooth the rocky relations between the university and citizens' groups whose concern about toxic emissions prompted public disclosure of the medical school's health and safety practices. The campus is in the heart of a residential district near San Francisco's Haight-Ashbury district.

The study may prove a model for universities elsewhere in the United States. UCSF officials say their environmental assessment is the most comprehensive ever undertaken by a medical centre, but, given increased public concern over the environment, other studies are sure to follow. The assessment was carried out by Radian Corporation, an independent company from Sacramento, which examined air, water and soil samples from on or near the campus. It found no detectable effect on air quality and concluded that chemicals in sewer water were a fraction of allowable government levels.

University vice-chancellor Bruce Spaulding says the study shows that medical facilities pose no significant risk to their neighbouring communities - and that the UCSF experience provides a lesson for similar facilities nationwide.

Kathe Traynor, who represents the Haight-Ashbury Improvement Association, says the new study bolsters UCSF's community relations around the present campus. But a planned move of the School of Pharmacy research laboratories to the Laurel Heights area of San Francisco is still at issue. A lawsuit filed by the Laurel Heights Improvement Association of San Francisco Inc. challenged the plan - and late last year the state supreme court ordered UCSF to undertake a new Environmental Impact Report (EIR) in order for the relocation to be approved (see Nature 336, 706; 1988).

Robert Buderi

SITUATION VACANT

\section{Still no taker for $\mathrm{NIH}$ directorship}

\section{Washington}

THE Bush Administration is still casting about for candidates to fill the post of director of the US National Institutes of Health (NIH). The top three candidates on the short list have declined the job.

Anthony Fauci, director of AIDS research at NIH and head of the National Institute of Allergy and Infectious Diseases, removed his name from the list two weeks ago. The drug company Merck has indicated through its press office that its president, P. Roy Vagelos, will not be leaving the company.

William H. Danforth, chancellor of Washington University in St Louis, has also asked not to be considered for the post. James B. Wyngaarden, the previous NIH director, resigned at the end of July.

Carol Ezzell 